\title{
A Maker-in-Residence Program to Build a Community of Makers
}

\section{Ms. Jewell Amanda Brey, University of North Carolina, Chapel Hill}

Undergraduate biomedical engineering student at the University of North Carolina Chapel Hill, graduating May 2017. Heavily involved with the BeAM University Maker Spaces and president of MakNet, the student maker organization on campus.

Ms. Danianne Mizzy, University of North Carolina, Chapel Hill

Dr. Richard Goldberg, University of North Carolina, Chapel Hill

Richard Goldberg is a Research Associate Professor and Associate Director of Undergraduate Studies in the Department of Biomedical Engineering. He teaches several instrumentation courses and a senior design class. His primary interest is in rehabilitation engineering and assistive technology for people with disabilities. 


\title{
A Maker-in-Residence program to build a community of Makers
}

\begin{abstract}
The BeAM (Be A Maker) Makerspace at the University of North Carolina at Chapel Hill hosts a Maker-in-Residence (MIR) program. Through this program, undergraduate students participate in design-build projects under the guidance of expert Makers who are skilled in a particular technology or craft. The goals are to foster interdisciplinary student collaboration and to provide students with the opportunity to learn and apply the hands-on skills promoted by the Maker culture. Each semester, a different Maker is selected through an application process. The Maker leads a small group of students through a series of hands-on fabrication workshops during the semester. When the project is complete, the program culminates in a capstone event that shares the project with the larger University community.

The MIR executive committee, which consists of 6-8 undergraduate students, leads and administers the program with faculty support. The committee issues the Call for Proposals for both Makers and student participants; conducts interviews and reference checks; helps to schedule and staff the build sessions; and plans and runs the capstone events. Makers receive an honorarium, project materials, a capstone event budget, and a small travel stipend. These expenses are partially funded by a small grant from the Parents Council and other donors.

The first MIR was an amateur astronomer who led students in the fabrication of a telescope. Using this telescope, more than 500 students and community members have been able to view the moon, planets and stars during the capstone event as well as other events both off campus and at the planetarium on campus. The second MIR was a local engineering professional who led workshops in the fabrication of Arduino-based musical circuits. Students played their resulting musical instruments together and exhibited them during a capstone event in the Makerspace. The third MIR recipient was a retired biologist and artist who led a project constructing native bee nesting units.

The program has been meeting its goals. Students from across the campus community have participated in the workshops and they represent a broad spectrum of academic majors. Students have gained new maker skills by participating in the program and have continued their involvement in the makerspace. Student participants filled out an evaluation survey and the results demonstrate that they had a positive experience that provided them with valuable fabrication skills. In addition, the capstone events have had high attendance and been well received by the community.
\end{abstract}

\section{Introduction}

Makers are self-reliant, skilled individuals that specialize in divergent thinking and creative problem solving. Well-versed in navigating from ideas to the tangible, makers may be artists, software programmers, fabricators, machinists, designers, or others. These professionals are experts in design-build thinking that is invaluable as a process, tool, and mindset across the university [1], [2]. Aiming to cultivate this "maker spirit", the makerspace is a valuable resource in the university setting. In addition to providing access to unique facilities, the makerspace fosters a culture of design and innovation, encouraging risk-taking and exploration [3]. Users 
work with diverse tools, seek out problems to solve, lead and teach, and share their passions and creations with a community [4].

With the support and determination of an interdisciplinary group of faculty and leaders from the sciences, arts, humanities, and libraries, the University of North Carolina at Chapel Hill (UNCChapel Hill) launched a network of makerspaces on campus in Fall 2015, called BeAM (Be A Maker). The BeAM network continues to expand in breadth and influence, gathering interest across the university. The Kenan Science Library features a makerspace and has been a pillar of the maker movement at the university. Acting as a facility but also as a facilitator of the maker community, the makerspace has the opportunity to support classroom education as well as to foster and empower an interdisciplinary community and culture to imagine, design and create.

The makerspace is an ideal location to implement the connected learning model, which features production-based, networked, and purpose-driven projects that enhance student engagement and learning and provide an exciting outlet for student passions [5]. Makerspaces support interestdriven, peer-supported, and academically oriented projects [5]. Furthermore, the specific outcomes and benefits resulting from interdisciplinary [6] and classroom-independent projects [7], [8], [9] have been demonstrated and continue to be defined.

As part of our efforts to foster the connecting learning model, we developed a Maker-inResidence program (MIR), hosted by the makerspace. Our goals for MIR were to provide an interdisciplinary learning experience for undergraduate students within the makerspace, and promote a culture of making at the university. These goals are consistent with the mission and values of the makerspace.

The MIR program enables a diverse group of undergraduate students to participate together in design-build projects under the guidance of expert makers skilled in a particular technology or craft. The Maker, by sharing their passion for their craft, inspires this dedicated set of students as they are led through a series of build sessions. Although the sessions are structured, participants are encouraged to self-direct and take ownership of their projects. Particularly at this university which has an engineering department but lacks an engineering school, the MIR series and the makerspace are designed to encourage collaboration between individuals with diverse interests and backgrounds that will enhance divergent thinking and creativity.

The student participants learn valuable, hands-on skills and commit to share the knowledge they have gained through conducting future workshops and/or volunteering. They become part of an interdisciplinary group, befriending fellow participants and forming a unique cross-disciplinary community. Projects are designed around a specific theme to increase the educational value and student engagement and to draw students from varied backgrounds with a range of making skills who otherwise might not have been introduced to or encouraged to use the makerspace. These students are exposed to skills and technology that one would not normally experience (wood and metal working, laser cutting, 3D printing, optics, electronics and painting), allowing students to pursue interests and develop knowledge and marketable skills. The experience also provides a means to develop other key skills including team-work, creativity, and problem-solving through interest-driven and peer-supported projects. Upon completion, the students share their work with the larger university community through a capstone demonstration, exhibition, or performance, acting as a way to broaden the impact of the project and increase engagement with the makerspace. Figure 1 is an example of the capstone event for the telescope project. 


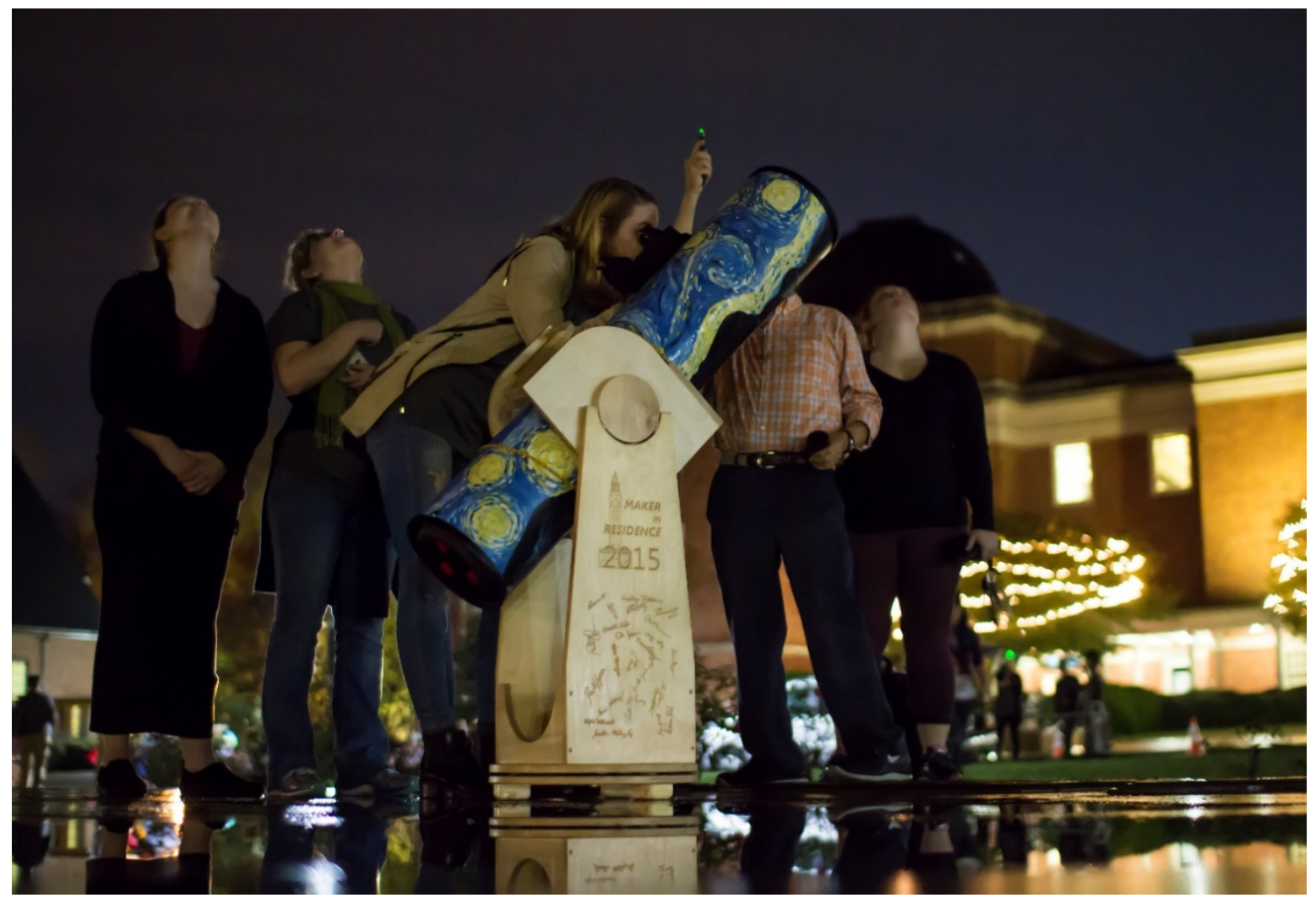

Figure 1: Fellow undergraduate students use the "Starry Night" telescope for the first time during the capstone event for the MIR telescope build project.

In particular, this paper focuses on the three completed Maker-in-Residence projects. Each was an independent project but was designed to meet the following objectives based on the connected learning model and to enhance participation in the makerspace:

- Fostering interdisciplinary collaboration

- Enabling engaging projects for students to learn and apply hands on skills

- Cultivating a casual and fun environment for building team-work, communication, and problem solving skills

- Enhancing proficiency with relevant practical skills and tools

- Expanding interest in the makerspace and maker community

Survey responses from the participants demonstrate that the program has met the objectives listed above, having a significant impact on student skills and confidence as well as providing a valuable experience for participants outside of the classroom. Furthermore, the program has produced impactful events and products for the university and community. 


\section{Methods}

The MIR series was designed with three tiers of student involvement, each of unique benefit to the students. The first tier is the student executive committee, which administers the MIR program through organization and facilitation, thereby developing leadership skills necessary to coordinate students from a variety of academic backgrounds. These students are in charge of project planning, execution, and evaluation, as well as developing improvements from one project to the next. They are tasked with issuing the Call for Proposal for makers and Call for Participation for students, conducting interviews and reference checks, selecting the maker and student participants, and are provided with an excellent exercise in student leadership. These students also staff the build sessions and plan and run the capstone events. The executive committee consists of 6-8 undergraduate students, and it leads and administers the program with faculty support.

The second tier of student involvement consists of the students directly participating in the project. Applications for interested students are released and subsequently reviewed by the executive committee. The participants are carefully chosen by the executive committee to be both interdisciplinary and to represent a wide range of maker experience, many with no prior fabrication experience. The number of students participating depends on the needs of the particular project. Additionally, due to the flexible and varied nature of the types of projects, the build session length and project duration are determined to best suit the individual projects. Working with and alongside each other, the students gain both hard and soft skills and have the opportunity to pursue interests outside of the classroom. The project encourages undergraduate participation to maximize facilities use for both personal and academic projects, and also builds and amplifies the maker community.

The general undergraduate population is the third tier that benefits from the completed projects. The campus-wide value of each project is demonstrated through capstone events to showcase each finished project. These large-scale, high-visibility capstone events are designed to inspire undergraduates to become involved in future projects and discover the potential of the maker community.

Each project is carefully chosen by the executive committee to maximize its impact on the university campus. In the Call for Proposals, Makers are asked to provide previous teaching experience and to define how each build session will meet program objectives within the time frame and budget. The Makers then continue to an interview with the executive board, which uses the following list of criteria to rate and select a Maker for the semester's project, specifically designed to prioritize student engagement, feasibility, and diversity.

1. How enthusiastic/interested do you think UNC undergraduates would be about this project? Are you excited about it?

2. Does the project target the interest of students from a wide range of backgrounds and interests? Target students we haven't already reached, or want to encourage to become involved in the space?

3. Do you think the project would be feasible to complete in the month of build sessions that we have? Would beginners and expert students alike feel useful, welcomed, and productive?

4. Does the maker seem genuinely enthusiastic? How unique is the project? Does the project benefit the university as a whole? 
5. Rank this project overall with respect to the others

6. Any other thoughts? Opinions? Comments?

The Maker is screened with an appropriate background check, a feasible schedule is agreed upon, and he or she receives an honorarium, project materials, a capstone event budget, and a small travel stipend. These expenses are partially funded by a small grant from the university's Parents Council as well as support from the library, the department which houses the makerspace and the University's Innovation unit and a local company. The Maker works alongside the Makerspace program manager to compile a detailed lesson plan and to maximize use of campus facilities.

Participant evaluations are used to provide both quantitative and qualitative feedback regarding the specific project and achievement of program objectives. For the Fall 2016 MIR project, quantitative evaluations were distributed to participants during the final build session after they had finished their projects (see figures $2 \mathrm{a}$ and $2 \mathrm{~b}$ ). Participants were asked to reflect back to before the project began to rate their confidence on skills on a Likert scale, and then consider their confidence at the conclusion of the project. In the future, a survey will be given to students at the first build session, and the same survey upon completion to measure competencies.

A statistical analysis of the survey results was performed. For each category considered, the data was first tested for normality. For normally distributed data sets, a paired t-test was used. For the data that was not normal, the Wilcoxon R-S test was used to test for significance. A p-value less than 0.05 was considered statistically significant.

If you can think back to the time before you started working on the project, please rate your confidence level for the following:

\begin{tabular}{|l|l|l|l|l|l|}
\hline & $\begin{array}{c}\text { high } \\
\text { confidence }\end{array}$ & $\begin{array}{c}\text { somewhat } \\
\text { confident }\end{array}$ & neutral & $\begin{array}{c}\text { low } \\
\text { confidence }\end{array}$ & $\begin{array}{c}\text { zero } \\
\text { confidence }\end{array}$ \\
\hline $\begin{array}{l}\text { Design skills/ design } \\
\text { process (ideate, } \\
\text { research, sketch) }\end{array}$ & & & & & \\
\hline $\begin{array}{l}\text { General making skills } \\
\text { (wood/metal/plastic) }\end{array}$ & & & & & \\
\hline $\begin{array}{l}\text { Making a tangible item } \\
\text { starting with idea }\end{array}$ & & & & & \\
\hline $\begin{array}{l}\text { Using the tools in the } \\
\text { makerspace }\end{array}$ & & & & & \\
\hline $\begin{array}{l}\text { Being able to learn to use } \\
\text { new tools/ learn new } \\
\text { skill }\end{array}$ & & & & & \\
\hline $\begin{array}{l}\text { Overcoming problems } \\
\text { that arise during a } \\
\text { project }\end{array}$ & & & & & \\
\hline
\end{tabular}

Figure 2a: First part of survey administered to evaluate completion of objectives. 
Now that you have completed the project, please rate your confidence level for the following:

\begin{tabular}{|l|l|l|l|l|l|}
\hline $\begin{array}{l}\text { high } \\
\text { confidence }\end{array}$ & $\begin{array}{c}\text { somewhat } \\
\text { confident }\end{array}$ & neutral & $\begin{array}{c}\text { low } \\
\text { confidence }\end{array}$ & $\begin{array}{c}\text { zero } \\
\text { confidence }\end{array}$ \\
\hline $\begin{array}{l}\text { process (ideate, } \\
\text { research, sketch) }\end{array}$ & & & & & \\
\hline $\begin{array}{l}\text { General making skills } \\
\text { (wood/metal/plastic) }\end{array}$ & & & & & \\
\hline $\begin{array}{l}\text { Making a tangible item } \\
\text { starting with idea }\end{array}$ & & & & & \\
\hline $\begin{array}{l}\text { Using the tools in the } \\
\text { makerspace }\end{array}$ & & & & & \\
\hline $\begin{array}{l}\text { Being able to learn to use } \\
\text { new tools/ learn new } \\
\text { skill }\end{array}$ & & & & & \\
\hline $\begin{array}{l}\text { Overcoming problems } \\
\text { that arise during a } \\
\text { project }\end{array}$ & & & & & \\
\hline
\end{tabular}

Figure 2b: Second part of survey administered to evaluate completion of objectives.

\section{Results}

The Maker-In-Residence program has been run three times, once per academic semester beginning in Fall 2015 and continuing through Fall 2016, with plans to continue this program each semester in the future. Figure 3 shows the number of participants in each build and capstone event. Each experience has been valuable for participants, the executive committee, and produced noteworthy events and products for the university and community.

\begin{tabular}{lcc}
\hline Project & $\begin{array}{l}\text { Participants of } \\
\text { the build }\end{array}$ & $\begin{array}{l}\text { Participants in } \\
\text { Capstone Event } \\
\text { (approximate) }\end{array}$ \\
\hline Telescope Build & 15 & 400 \\
Musical Circuits & 40 & 150 \\
Sculptural Bee Nesting Unit & 12 & 60 \\
\hline \hline
\end{tabular}

Figure 3: Participants of the build and capstone events for the first three MIR projects 
A total of 15 undergraduate students participated in the first MIR program, a telescope build project (figures 4-5). Throughout each session, the maker and amateur astronomer and additional makerspace staff introduced novel skills to participants such as sanding, drilling, mounting and aligning the optics. Students were then encouraged to practice and implement these skills and to feel encouraged to design. For example, participants collaboratively painted the tube and laser etched designs into the wood base. In the final build session, the local planetarium gave participants training on how to instruct the public when interacting

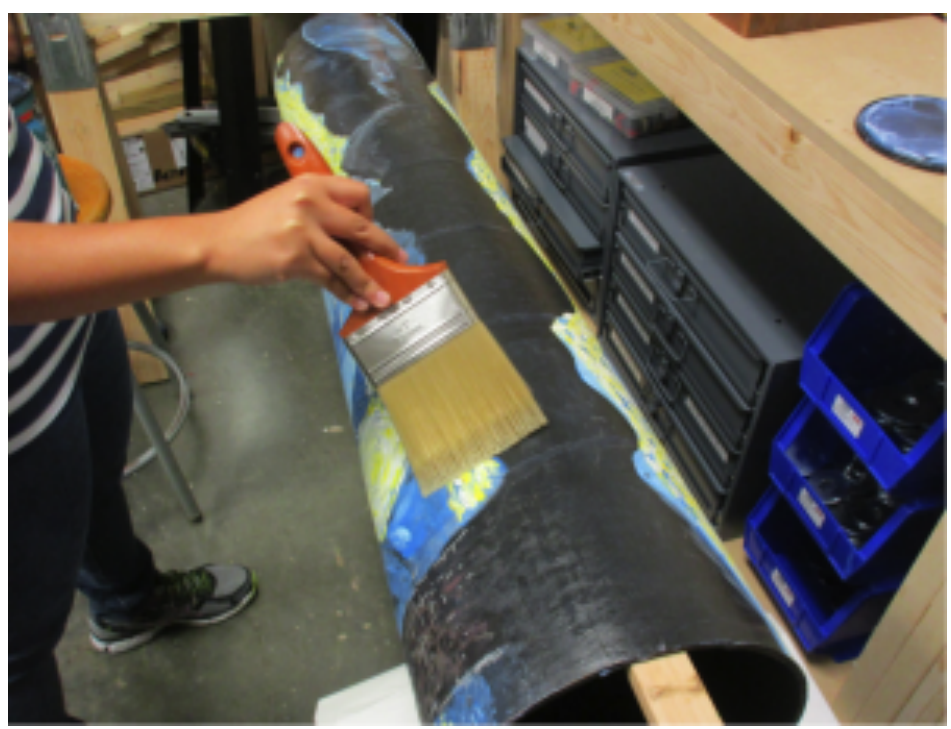

Figure 4: Participants apply protective polyurethane coat to the telescope. with the telescope. The project culminated with a capstone event that was held in partnership with the university's planetarium event for undergraduate students. Typically underutilized, this joint event at the planetarium with a student-made telescope and skydome planetarium show helped attract undergraduates to learn about astronomy.

More than 440 students were estimated to attend the event over the course of the evening, and many of these students (approximately half) stopped by the telescope during the course of the event to view the moon, the Andromeda galaxy, Pleiades, and other notable astronomical objects with the freshly built telescope. The telescope continues to be used on campus and at starwatching events, enabling over 500 students and community members to view the moon, planets and stars through this hand-crafted telescope. The telescope is available to be checked-out and used by any student, and continues to a valuable resource at local events and for members of the university community. This was one of only three projects invited to be featured at the next meeting of the Parents Council, and the presentation was delivered by three undergraduates who had led it.

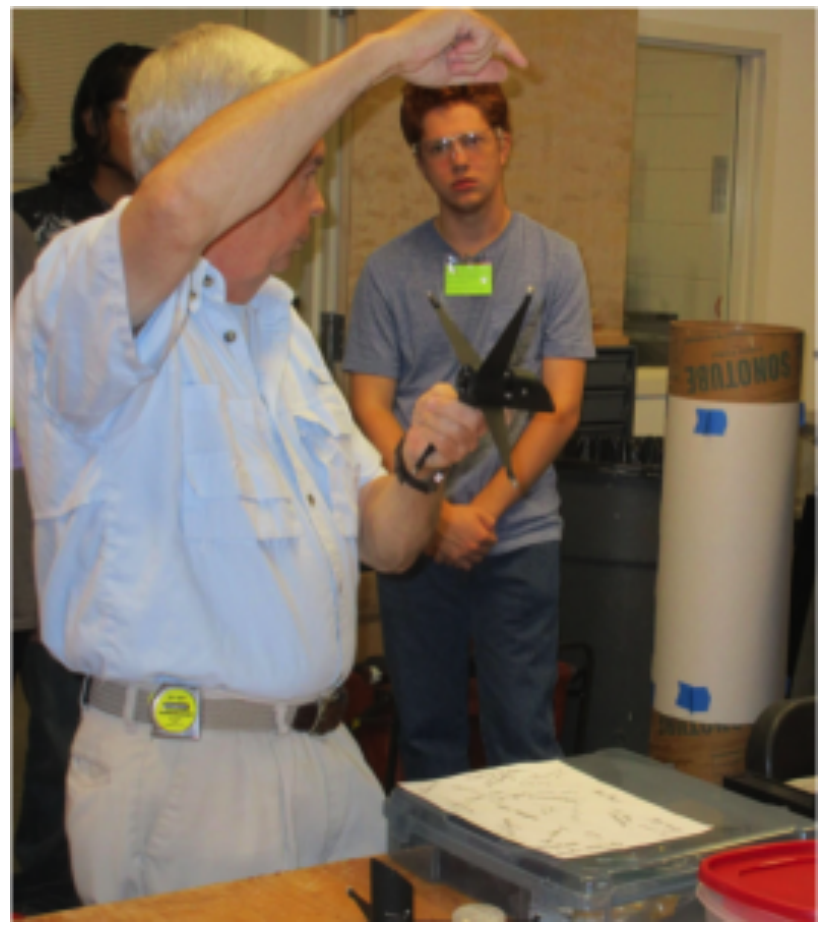

Figure 5. Maker Jim Pressley explains telescope optics and alignment. 
The second MIR program was Musical Circuits in Spring 2016 (see figure 6). This brought together a diverse set of 40 students with majors in everything from Earth Science to Ancient History. The combination of music, programming and engineering provided a unique experience that encompassed both the logic of science and the creativity of artistic expression. The event was done in partnership with the Experimental Music Study Group, a student group that bridges arts and sciences, engaging students from both UNC-Chapel Hill and nearby Duke University. While part of the workshop required instruction, much of the experience was students working together in a collaborative learning space. As opposed to the semester length projects, this project consisted

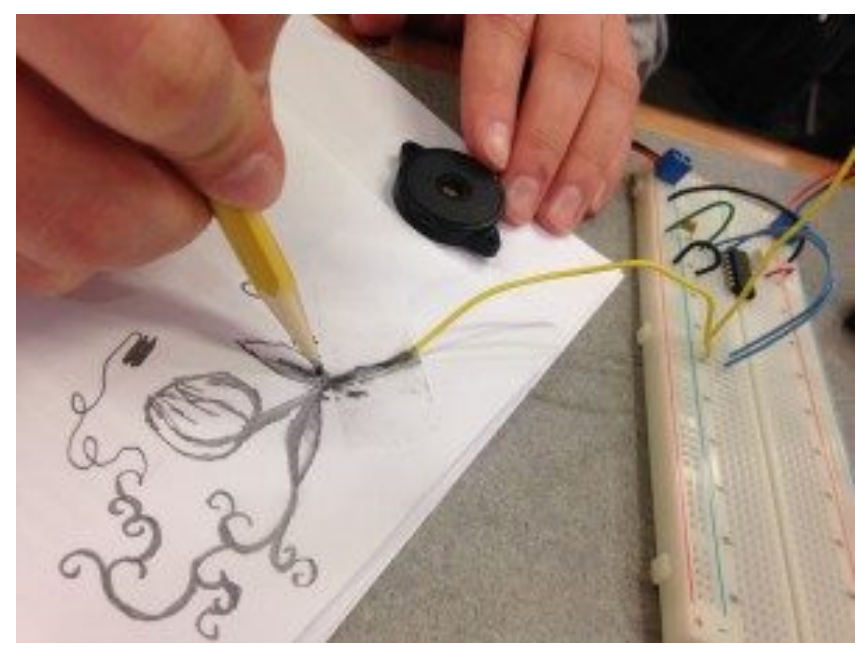

Figure 6: Art and science merge as students draw patterns that change the tone of the music in the musical circuit they have created.

of two independent sessions, catering to a

larger group of participants. Sessions were limited to 20 students based on the materials purchased. The capstone event was part of the makerspace launch, drawing about 150 people, many passing through the Musical Circuits demonstration and performance.

As part of the third semester's Maker-in-Residence project, 12 students designed and built sculptural nesting units for native bees. Throughout each of the five sessions, the maker and makerspace staff introduced novel hands-on skills to participants including sculpture design, drilling, metal working, riveting, laser cutting, 3D printing, and mounting. A faculty member from the entomology department from a nearby university volunteered her time to speak to the group on the role of bees in the ecosystem. The project culminated with a capstone event that was held in the makerspace, in which the students presented their favorite bee-related topic as they stood beside their own sculpture (see figure 7). Topics included our reliance on native bees for our food supply, types of bees and their behavior, as well as the threats humans pose to bees and steps we can take to mitigate this harm. An estimated 60 undergraduate students attended the event.

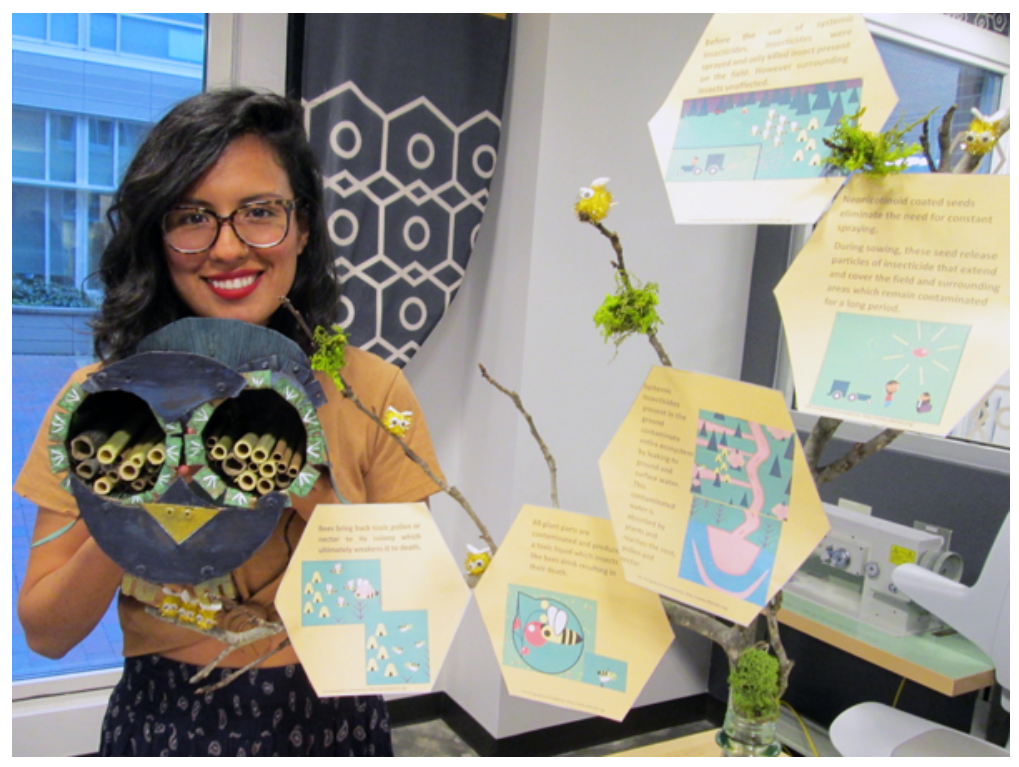

Figure 7: Participant proudly displays her owl-themed sculpture and bee nesting unit at the third project's capstone event 
Figures 8 and 9 show the diversity of participants in two of the three MIR projects. On the following page, Tables 1 and 2 show the survey results for the $3^{\text {rd }}$ MIR program, the sculptural bee nesting unit. While post-project survey data was collected for each of the three MIR programs, the questions concerning pre-project confidence levels were only included in the most recent program. Therefore, only the data for the $3^{\text {rd }}$ program is included here because it enables us to assess whether there were changes from pre-project to post-project.

\section{BY THE MAJOR: TELESCOPE BUILD}

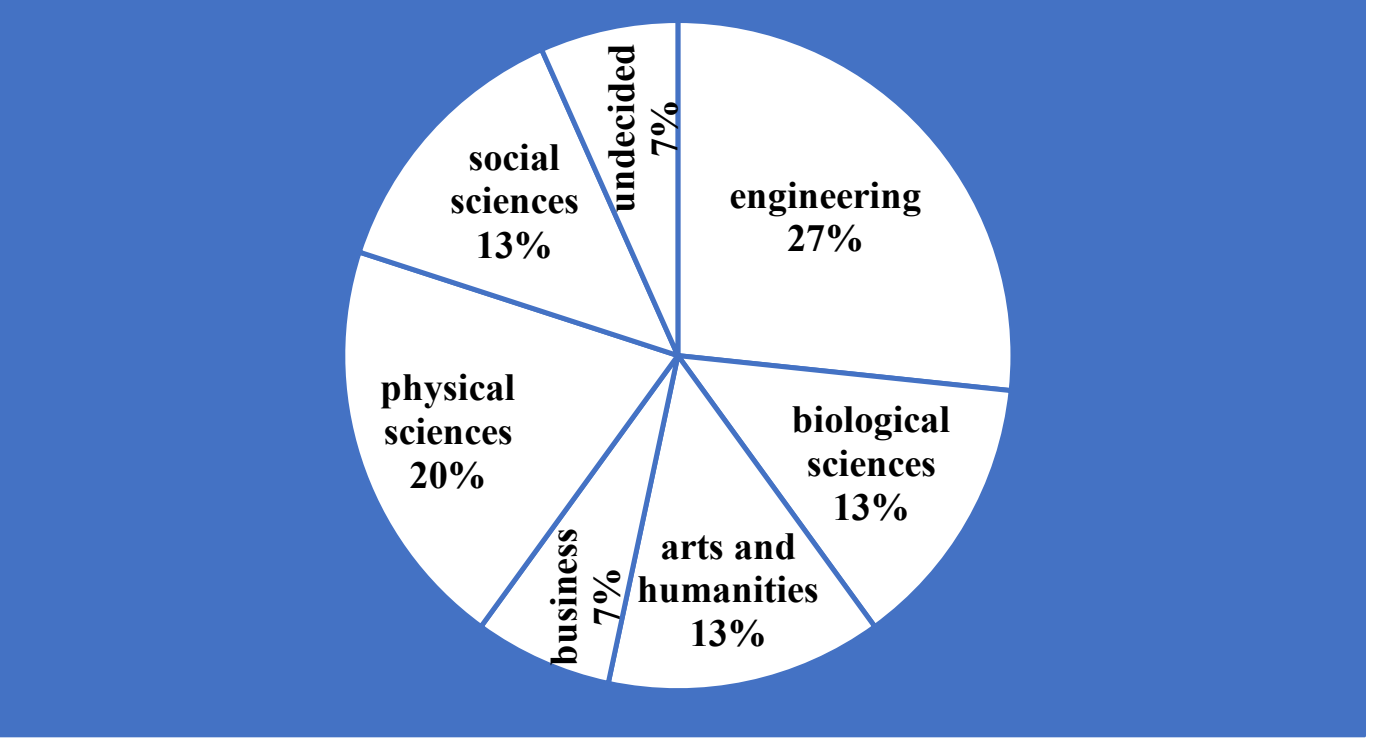

Figure 8: Breakdown of participants by major for first MIR project, the telescope build, with fifteen participants. Participants background is well distributed across all categories of majors.

\section{BY THE MAJOR: SCULPTURAL BEE NESTING UNIT}

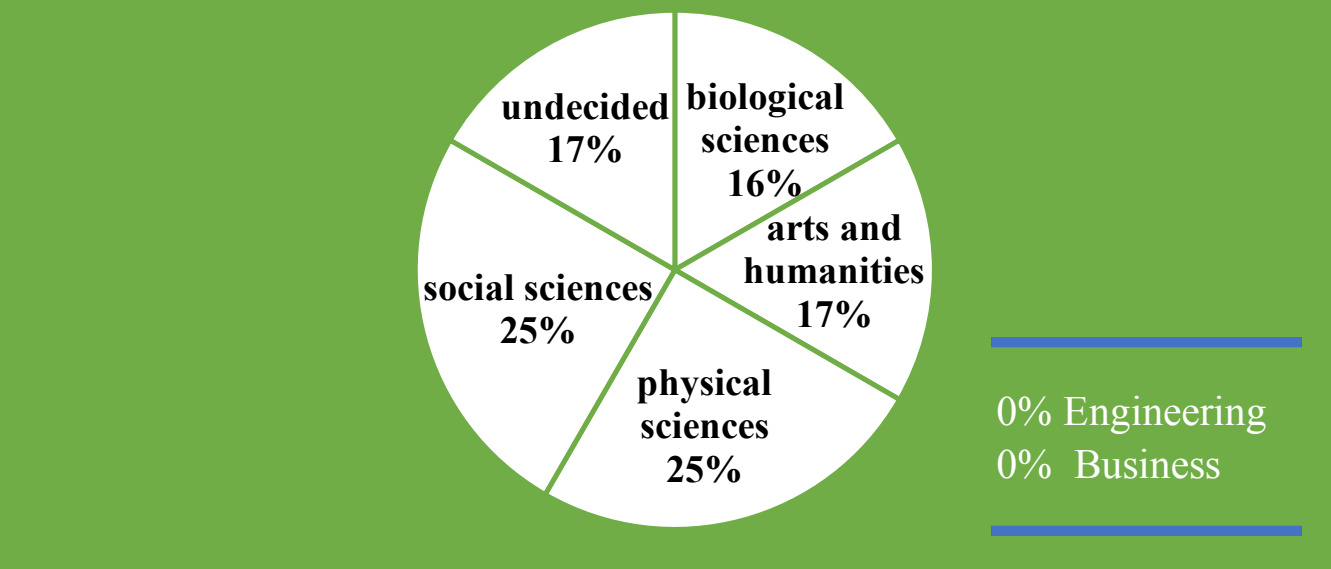

Figure 9: Breakdown of the 12 participants by major type for third MIR project, sculptural bee nesting units. Major categories not represented in the group include engineering and business. 


\begin{tabular}{|lcc|}
\hline Rate level of confidence for the following & Pre-project & Post-project \\
\hline $\begin{array}{l}\text { Design skills/ design process (ideate, } \\
\text { research, sketch)* }\end{array}$ & $3.86 \pm 1.07$ & $4.57 \pm 0.53$ \\
\hline General making skills (wood/metal/plastic)* & $3.43 \pm 0.98$ & $4.43 \pm 0.53$ \\
\hline Making a tangible item starting with idea & $4.00 \pm 1.15$ & $4.57 \pm 0.79$ \\
\hline Using the tools in the makerspace* & $2.43 \pm 1.40$ & $4.14 \pm 0.90$ \\
\hline $\begin{array}{l}\text { Being able to learn to use new tools/ learn } \\
\text { new skill }\end{array}$ & $4.00 \pm 1.15$ & $4.57 \pm 0.53$ \\
\hline $\begin{array}{l}\text { Overcoming problems that arise during a } \\
\text { project }\end{array}$ & $3.86 \pm 1.21$ & $4.57 \pm 0.53$ \\
\hline
\end{tabular}

Table 1: Participant evaluation results regarding confidence of skills before and after for sculptural bee nesting unit project. Seven students completed the survey, $n=7$. A Likert scale was used, $5=$ high confidence, $1=$ zero confidence. $(*)$ signifies that an unpaired t-test or Wilcoxon S$\mathrm{R}$ test for not normally distributed data showed a statistical significance $(\mathrm{p}<0.05)$ in the post vs. pre-project results.

\begin{tabular}{|lc|}
\hline $\begin{array}{l}\text { Rate to what extent the project achieved these } \\
\text { objectives }\end{array}$ & $\begin{array}{c}\text { average and } \\
\text { standard deviation }\end{array}$ \\
\hline Gained new hands-on skills & $3.63 \pm 0.52$ \\
\hline Had opportunity to be creative & $4 \pm 0$ \\
\hline Problem solving skills & $3.50 \pm 0.75$ \\
\hline Learned a skill you wouldn't have learned otherwise & $3.50 \pm 1.07$ \\
\hline Had impact on the university & $3.38 \pm 0.74$ \\
\hline Communication skills & $3.25 \pm 0.71$ \\
\hline Team-work skills & $3.13 \pm 0.64$ \\
\hline Could you teach the skills learned to others? & $3.75 \pm 0.46$ \\
\hline Informed undergraduates on current relevant issues & $3.88 \pm 0.35$ \\
\hline
\end{tabular}

Table 2: Participant survey results regarding level of achievement of project objectives for sculptural bee nesting units project. Eight students completed this part of the survey, n=8. A Likert scale was used, 4=highly achieved, 1=not achieved. 
In Table 1 above, it can be noted that all means increased from pre to post project, but a significance measure to compare means should ultimately be used. For each category, the data was first tested for normality, which would allow a t-test to be used. Results for confidence in general making skills, using the tools in the makerspace, and design skills were each normally distributed data sets and a paired t-test showed that confidence levels were significantly increased from pre- to post-project for each $(\mathrm{p}<0.05)$. For the data that was not normally distributed, the Wilcoxon R-S test was used. This test did not indicate a significant difference in the categories from pre- to post-project. Although limited by the small sample size, these tests show significant changes in confidence levels across three of six catergories. Future metrics will be implemented and analyzed once more participants are surveyed.

The information from Table 2 demonstrates the extent to which the project achieved its objectives. All categories were rated on average between highly achieved and somewhat achieved, the top three categories being creative expression, ability to teach the skills they learned, and the connection of the project to relevant issues.

\section{Discussion}

The program is meeting its objectives. Interdisciplinary collaboration has been accomplished by selecting students to represent a variety of backgrounds. Figures 8 and 9 show the varied representation of student majors of participants involved in the two longer-term projects. Majors were classified into groupings of social sciences (ex. political science, sociology, geography), physical sciences (ex. physics, chemistry, environmental science), business, arts and humanities (studio art, art history), engineering, biological sciences (ex. biology, biostatistics, agriculture), and undecided. Students have expressed the value and unique experience of working in such a diverse environment. In a participant survey from the telescope project, one student stated "it's really fun to work with such a diverse crowd and build things with my hands."

Within this unique interdisciplinary environment, participants complete engaging projects and learn and apply hands-on skills. Recent quantitative survey results from the sculptural bee nesting project further demonstrate that the program is meeting objectives to enhance proficiency with relevant practical skills and tools. The survey results show distinct changes in confidence of student's skills before and after the project. General making skills, using the tools in the makerspace, and design skills showed a significant change from pre to post project. A student in the telescope build project reports that following the project they "feel really well trained and equipped to use my new skills."

In addition to participant confidence levels, skills objectives were rated on average between highly achieved and somewhat achieved (table 2), the top three categories being the implementation of creative expression, participants' ability to teach the skills they learned, and the connection of the project to relevant issues. Participants also expressed that through the project they exercised their problem-solving skills, communication and team-work skills, learned a skill they wouldn't have otherwise, and had a university-wide impact.

In the future, the pre- and post-project surveys will be administered for each program and we will require this for all participants to enable more comprehensive assessment. In addition, we can then compare the relative impact of each program to determine which ones were most effective in achieving our objectives. 
Qualitative survey responses so far show that the program has successfully cultivated a casual and fun environment for building team-work, communication, problem solving skills. Many students expressed that they were surprised and grateful about how much they learned, either in astronomy or about the environmental impact of bees. Most participants felt this was a valuable experience and that they would participant in future MIR projects given the chance. One participant expressed gratitude for the creative liberty offered and that she "was never told no and was motivated to think outside of the box." Another participant said the project "was worthwhile and fun and it educated people about things. It's like what college should be."

One of the major successes of the program has been the continuing involvement of participants in the makerspace community following the completion of their project. In fact, four of the eight students holding leadership positions in the student maker club in 2016-2017 were participants in the first MIR series. This group is composed of students passionate about the maker community and they serve as ambassadors of the makerspace. Additionally, the executive committee of the MIR series is also about $50 \%$ composed of past MIR participants. These trends show that the project is gathering interest and passion for the makerspace community at the university. There is currently no method in place to measure learning gains as a result of continued involvement, but as the program becomes more established, the committee will consider methods to capture longer term gains.

Qualitative feedback from students from each project is also a useful metric and tool for designing future programs. The committee received valuable feedback on the ideal length and times for this type of project from the surveys, as well as information to improve the program. One participant from the sculptural bee nesting unit project, in dictating what skills are required to be a successful maker to lead the project cite "experience, patience and to be able to help when needed" as important skills. In the future, we hope to bring makers to campus for a true residency over a multi-week period.

The series was bolstered by flexible and well-supported facilities in the BeAM makerspace network, by the grants that provided funds for this program, and by institutional support from Kenan Science Library at UNC-Chapel Hill. Although not necessarily required, these foundations may be helpful in launching a similar program.

\section{Summary}

Through the Maker-In-Residence program, students at UNC-Chapel Hill are given the unique opportunity to work with a passionate, skilled maker, to participate in design-build projects, to learn valuable skills and gain memorable experiences. These projects foster interdisciplinary student collaboration and provide students with the opportunity to learn and apply hands-on skills. The project has seen great success in the three iterations that have been run so far.

Students from across the UNC-Chapel Hill community have participated in the workshops, coming from a variety of academic majors. The workshops take place in the BeAM (Be A Maker) facilities at UNC-Chapel Hill. Students have gained new Maker skills by participating in the program and have continued their involvement in the Makerspace. Student participants completed an evaluation survey and the results demonstrate that they had a positive experience through which they gained valuable skills. Additionally, the capstone events have had high attendance and been well-received by the community. Not only were student participants enthusiastic during the projects, but many continue to be involved in the maker community 
following completion, sharing their passion and expanding their creative problem-solving, design, and manufacturing skills.

\section{References}

[1] W. Brenner and F. Uebernickel, Design thinking for innovation : research and practice. Cham: Springer Science and Business Media, 2016.

[2] R. Cooper, S. Junginger, and T. Lockwood, "Design thinking and design management: A research and practice perspective," Des. Manag. Rev., vol. 20, pp. 46-55, 2009.

[3] L. Fleming, “A Maker Culture.," Principal, vol. 95, no. 4, pp. 16-19, 2016.

[4] K. M. Imberly Sheridan, E. K. Rosenfeld Halverson Breanne Litts, and L. Nette Jacobs priebe, "Learning in the Making: A Comparative Case Study of Three Makerspaces," Harv. Educ. Rev., vol. 84, no. 4, 2014.

[5] L. Carfagna, "Beyond Learning-As-Usual: Connected Learning Among Open Learners Lindsey 'Luka' Carfagna - Google Books,” Irvine, CA, 2014.

[6] N. A. Baine, N. Baine, and H. Qi, "Using the Maker Concept to Promote Multidisciplinary Skills in a Freshman Engineering Program," ASEE's 123rd Annu. Conf. Expo., vol. 14969, 2016.

[7] T. M. Katona, J. L. York, and R. S. Crockett, "Innovation Sandbox: Examining the Impact of Interdisciplinary Innovation Spaces on Diverse Disciplines."

[8] P. S. Wardrip and L. Brahms, "Learning Practices of Making: Developing a Framework for Design."

[9] M. Magdalini, Z. Lagoudas, M. Lagoudas, J. E. Froyd, and J. L. Wilson, “Assessing Impact of Maker Space on Student Learning." 